\title{
Traffic-related air pollution, biomarkers of metabolic dysfunction, oxidative stress, and CC16 in children
}

\author{
Amy L. Zhang (D) ${ }^{1}$, John R. Balmes ${ }^{1,2,3}$, Liza Lutzker ${ }^{1}$, Jennifer K. Mann ${ }^{1}$, Helene G. Margolis ${ }^{4}$, Tim Tyner ${ }^{5,6}$, Nina Holland ${ }^{1}$, \\ Elizabeth M. Noth ${ }^{1}$, Fred Lurmann ${ }^{7}$, S. Katharine Hammond ${ }^{1}$ and Stephanie M. Holm ${ }^{1,2,3 凶}$
}

(c) The Author(s) 2021

BACKGROUND: Previous research has revealed links between air pollution exposure and metabolic syndrome in adults; however, these associations are less explored in children.

OBJECTIVE: This study aims to investigate the association between traffic-related air pollutants (TRAP) and biomarkers of metabolic dysregulation, oxidative stress, and lung epithelial damage in children.

METHODS: We conducted cross-sectional analyses in a sample of predominantly Latinx, low-income children $(n=218)$ to examine associations between air pollutants (nitrogen dioxide $\left(\mathrm{NO}_{2}\right)$, nitrogen oxides $\left(\mathrm{NO}_{x}\right)$, elemental carbon, polycyclic aromatic hydrocarbons, carbon monoxide (CO), fine particulates $\left(\mathrm{PM}_{2.5}\right)$ ) and biomarkers of metabolic function (high-density lipoprotein $(\mathrm{HDL})$, hemoglobin $\mathrm{A} 1 \mathrm{c}(\mathrm{HbA1c})$, oxidative stress (8-isoprostane), and lung epithelial damage (club cell protein 16 (CC16)).

RESULTS: $\mathrm{HDL}$ cholesterol showed an inverse association with $\mathrm{NO}_{2}$ and $\mathrm{NO}_{x}$, with the strongest relationship between $\mathrm{HDL}$ and 3-month exposure to $\mathrm{NO}_{2}\left(-15.4 \mathrm{mg} / \mathrm{dL}\right.$ per IQR increase in 3-month $\left.\mathrm{NO}_{2}, 95 \% \mathrm{Cl}=-27.4,-3.4\right)$. 8-isoprostane showed a consistent pattern of increasing values with 1-day and 1-week exposure across all pollutants. Non-significant increases in \% $\mathrm{HbA} 1 \mathrm{c}$ were found during 1-month time frames and decreasing CC16 in 3-month exposure time frames.

CONCLUSION: Our results suggest that TRAP is significantly associated with decreased HDL cholesterol in longer-term time frames and elevated 8-isoprostane in shorter-term time frames. TRAP could have the potential to influence lifelong metabolic patterns, through metabolic effects in childhood.

Keywords: Traffic-related Air Pollution; Early Life Childhood Exposure; Oxidative Stress; Metabolic Dysregulation; Polycyclic Aromatic Hydrocarbons; Low-SES Populations

Journal of Exposure Science \& Environmental Epidemiology (2022) 32:530-537; https://doi.org/10.1038/s41370-021-00378-6

\section{INTRODUCTION}

Growing evidence suggests a link between $\mathrm{PM}_{2.5}$ exposure and metabolic dysfunction at a population level [1]. Metabolic syndrome and its components, such as insulin resistance, central adiposity, elevated blood pressure, and dyslipidemia [2], have all been shown to have a positive association with air pollution exposure [3-7]. This is thought to be due to higher levels of oxidative stress [8-10] and upregulated inflammatory responses in tissues of distant organs, such as the liver, pancreas, and adipose tissue $[4,6]$. These processes can lead to clinically harmful effects such as glucose intolerance related to insulin resistance and increased cardiovascular morbidity [6, 11-14].

While the relationship between traffic-related air pollution (TRAP) and effects on metabolic dysregulation is well studied in adults, there are still gaps in the literature concerning these effects in children. TRAP is a category of pollutants that are emitted from motor vehicle emissions that result from fossil fuel combustion, and has been associated with adverse health effects in adulthood, such as metabolic and cardiovascular diseases [15]. Since childhood or prenatal exposures to TRAP have been hypothesized to contribute to metabolic syndrome in adults, health effects of these exposures in children have the potential to contribute to childhood disease as well as to long-term risk of adult diseases $[16,17]$. Adolescent cohort studies have demonstrated significant associations between TRAP exposure and the risk factors for Diabetes Mellitus Type II, such as lower insulin sensitivity and higher abdominal adiposity, fasting insulin, and fasting glucose $[6,18,19]$. Currently, the hypothesized biological mechanism behind this association is that localized lung inflammation may trigger oxidative stress and an inflammatory response, which spills over to the circulatory system. This increases systemic inflammation, leading to adverse metabolic and cardiovascular health effects $[4,12]$. More research is needed in this area to elucidate and confirm this suspected relationship, especially in pediatric cohort studies to gauge the effect of early-life exposure to traffic air pollution on later development of metabolic syndrome.

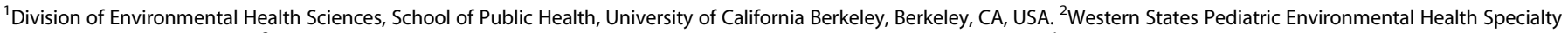

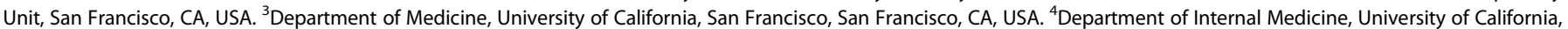

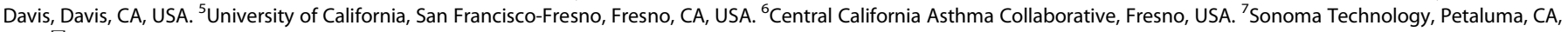
USA. ${ }^{\circledR}$ email: stephaniemholm@berkeley.edu 
The Children's Health and Air Pollution Study (CHAPS) is a research project focused on the adverse health effects of exposure to air pollution in childhood in Fresno, California. Located at the center of the San Joaquin Valley, Fresno residents are exposed to some of the worst air pollution in the United States [20]. Moreover, the city also has high rates of poverty and a large Hispanic/Latinx population [21]: groups that are often disproportionately affected by air pollution exposures due to close proximity to traffic sources [22]. This paper investigates the relationship between exposure to TRAP and several biomarkers of lipid and glucose metabolism (high-density lipoprotein (HDL) and hemoglobin A1c (HbA1c)), oxidative stress (urinary 8-isoprostane), and airway injury (club cell protein 16 (CC16)) in a population of low socioeconomic status, mostly Latinx children with an average age of 9.5 years. The aim is to build upon an earlier CHAPS analysis that assessed data from the cohort at age 7 and found significant associations between longer-term exposures between TRAP and $\mathrm{HbA} 1 \mathrm{c}$ and systolic blood pressure, as well as shorter-term exposures between TRAP and urinary 8-isoprostane [23]. This follow-up cross-sectional analysis is focused on biomarker data from visits 2 years after that baseline visit, including new biomarkers not measured previously (HDL and CC16). We hypothesized that we would see similar patterns related to TRAP exposure in these biomarkers as was seen in the prior analyses (increases in $\mathrm{HbA1c}$ and systolic blood pressure), with decreases in HDL and changes in CC16 that could be time-frame dependent (increases in the short-term with decreases associated with longer-term exposures).

\section{METHODS \\ Study population}

The data for these analyses were collected during the CHAPS, a prospective cohort study assessing the impact of air pollution on the health of children living in the Fresno metropolitan area. This study originally recruited 6- to 8-year-old children from elementary schools in Fresno during 2015-2017. Of the 299 children initially recruited into the cohort, $73 \%$ were retained and had a visit approximately 2 years later which resulted in the 8- to 10-year-old study population for this project (Supplementary Fig. 1). The details of the recruitment process are presented in a prior publication [23]. A subset of the CHAPS participants $(n=122)$ had an additional biomarker (CC16) assessed when additional funding became available.

At the follow-up study visit, each child participant's parent or guardian was interviewed using a detailed, structured health and general history questionnaire, and for each child participant, a non-fasting blood sample and urine sample were obtained. The questionnaire was offered to participants' parents or guardians in either English or Spanish and assessed participant demographics, including sex, age, and race/ethnicity, in addition to parental socioeconomic indicators such as annual household income, parental education levels, parental employment, and home ownership. Standing height was measured with a stadiometer and weight with a digital scale; from these BMI was calculated to use in describing the cohort [24]. All study protocols were approved by the Institutional Review Boards at the University of California, Berkeley and Stanford University.

\section{Outcome measurement}

Blood specimens were collected by venipuncture by a trained phlebotomist, with serum collected in serum separator tubes and whole blood collected in EDTA vacutainers (Becton, Dickinson and Company, Franklin Lakes, NJ). The samples for $\mathrm{HDL}$ (measured in $\mathrm{mg} / \mathrm{dL}$ ) and \% $\mathrm{HbA} 1 \mathrm{c}$ measurement were retrieved at room temperature within $24 \mathrm{~h}$ of draw and assayed by a commercial laboratory (LabCorp) using standard clinical laboratory techniques. In order to minimize participant burden and maximize study participation, the study's selection of biomarkers did not require children to fast before the visit and blood draws. Urine collected to assay 8-isoprostane, CC16, and creatinine was shipped overnight on a gel pack within $24 \mathrm{~h}$, or frozen before shipping to the Holland laboratory at UC Berkeley for urine analysis.

CC16 was assayed for a subset of participants at the same time as the CHAPS 9-year-old visit. CC16 was determined in urine by a commercially available ELISA kit (IBL-America, Minneapolis, MN). Samples were analyzed in duplicate, according to the manufacturer's protocol, and additional quality controls included random repeats and lab controls. The limit of detection (LOD) for the CC16 assay was $2 \mathrm{ng} / \mathrm{mL}$. The variability in readings (coefficient of variation) was $6.5 \%$ for duplicates and the random repeats were also within $10 \%$. Creatinine concentrations were determined in urine using commercially available ELISA (Oxford Biomedical Research, MI). Samples were randomized across plates and the coefficient of variation for creatinine was less than $3 \%$. There is debate about whether CC16 measurements should be adjusted for creatinine [25], thus a CC16/ creatinine ratio was also calculated for use in a sensitivity analysis.

Urinary total 8-isoprostane was measured in the banked samples using an ELISA kit (Oxford Biomedical Research, Rochester Hills, MI) as previously described [26]. Briefly, urine samples were pre-treated with betaglucuronidase (Oxford Biomedical Research, Rochester Hills, MI) prior to running the ELISA. The LOD for 8-isoprostane concentration was $0.08 \mathrm{ng} /$ $\mathrm{mL}$. Undetected oxidative stress measures were replaced with the LOD divided by the square root of 2 . Additional quality assurance/quality control provisions included repeats of $5 \%$ of samples and blanks, and internal lab controls with good reproducibility of 8-isoprostane (coefficient of variation $<7 \%$ ). Samples were randomized across plates and the coefficient of variation for creatinine was less than 3\%. All 8-isoprostane concentrations were adjusted to account for urinary dilution by dividing 8-isoprostane concentrations $(\mathrm{ng} / \mathrm{mL})$ by creatinine levels $(\mathrm{mg} / \mathrm{dL})$ with results reported in $\mathrm{ng} / \mathrm{mg}$ creatinine.

\section{Air pollution exposure assessment}

Two methods were used to model outdoor residential air pollution exposure-interpolation using inverse distance-squared weighting (for carbon monoxide (CO) and particulate matter with aerodynamic diameter of $<2.5 \mathrm{~m}\left(\mathrm{PM}_{2.5}\right)$ ) and regression modeling (for all other pollutants we considered). Complete residential address history was obtained from participating families and exposure was matched to participants' residential street addresses. Each address was then geocoded using ESRI (Environmental Systems Research Institute) software (Redlands, CA) or Google Earth, to develop a lifetime, residential history of each participant. Individual pollutant exposures were calculated for different time periods: 1-day, the average pollutant exposure concentration in the $24 \mathrm{~h}$ from noon the day of biospecimen collection to noon the day prior to when the biospecimen was obtained from the participant; mean week, which is average pollutant exposure the week before study date; 1-, 3-, and 6-month averages, which are the average exposures for each of these monthly intervals prior to the study date (e.g., the 1-month average represents the average daily exposure during the month prior to the study date); and 1-year average, which is average exposure the year before study date. The major source of these pollutants in Fresno is on-road traffic, not commercial, industrial, or off-road mobile sources [27].

Linear regression with mixed effects (random and fixed) was used to develop spatiotemporal models of daily average concentrations for PAH456, elemental carbon (EC), nitrogen dioxide $\left(\mathrm{NO}_{2}\right)$, and nitrogen oxides $\left(\mathrm{NO}_{\mathrm{x}}\right)$ incorporating data from field sampling campaigns in Fresno and Clovis [28, 29]. Briefly, hourly, quality-assured ambient pollutant (CO, $\mathrm{NO}_{2}, \mathrm{NO}_{x}$, and $\mathrm{PM}_{2.5}$ ) concentration and meteorological data collected at the local air pollution control district's Fresno central site monitoring station (First St./Garland) and three other sites in Fresno were obtained from the U.S. Environmental Protection Agency's Air Quality System [30]. EC and the sum of polycyclic aromatic hydrocarbons with 4, 5, and 6 rings (fluoranthene, benz[a]anthracene, chrysene, benzo[a]pyrene, benzo[b] fluoranthene, benzo[k]flouoranthene, benzo[ghi]perylene, indeno[1,2,3cd]pyrene, and dibenz[a,h]anthracene; abbreviated PAH456) were monitored as described in a prior publication, which also discusses further details describing the CHAPS air pollution exposure assessment methods [23].

\section{Statistical analysis}

All four biomarker outcomes were continuous variables. To quantify a relationship between biomarker levels and air pollutant exposures, regression analyses were conducted in the statistical programming language $\mathrm{R}$ version 4.0.4, using the packages ggplot2, gridExtra, lubridate, tidyverse, and tinytex for data manipulation/presentation, and the packages mgcv, splines, and corrarray for assessing associations between variables. Generalized additive models were used, with a p-spline smoothing function to account for seasonality. Distributions of 8isoprostane:creatinine ratio and $\mathrm{CC} 16$ were right-skewed; to normalize both distributions, we conducted a log transformation of these outcome 
variables. Confounding variables were chosen using a directed acyclic graph (Supplementary Fig. 2) and prior knowledge [23]. All models were adjusted for the following covariates: whether the child lives with a smoker, whether the child is Latinx, physical activity, household income, and the smoothed term for the day of the study. Sensitivity analyses were performed to assess differences based on creatinine adjustment of CC16 and choice of the smoothing function for seasonality. Model results are presented for a single interquartile range (IQR) change in that pollutant, for the given exposure average (IQR values are listed in each of the results tables as well as in Supplementary Table 1).

\section{RESULTS}

The study cohort consisted of 218 children: $46.8 \%$ of the sample was female, and $81.7 \%$ was Latinx (Table 1 ). This was a sample with low socioeconomic status; $24.3 \%$ of the study participants were from a family with $<\$ 15,000$ annual household income, and $70 \%$ of the study population did not own a home. Summary characteristics (median, 25th percentile, 75th percentile) for pollutant exposures are presented in Supplementary Table 1 and for outcome biomarkers in Supplementary Table 2.

Correlation matrices of outcome variables and exposure correlations by pollutant and exposure duration are shown in Supplementary Table 3a, b. $\mathrm{NO}_{2}, \mathrm{PAH} 456, \mathrm{CO}$, and $\mathrm{PM}_{2.5}$ were highly correlated from 1-month through 6-month exposure averages, and $\mathrm{NO}_{2}$ and $\mathrm{NO}_{x}$ were very highly correlated from 1-week through 6-month exposure averages. Due to these correlations and the large number of pollutant-outcome relationships assessed, results are interpreted as the effect of TRAP, by

Table 1. Socio-demographic characteristics of the CHAPS cohort (at the 9-year-old visits).

\begin{tabular}{|c|c|}
\hline Characteristics & No. $(\%)$ or mean [SD] \\
\hline Study cohort size & 218 \\
\hline Age, mean $[S D]$ & $9.46[0.62]$ \\
\hline Girls (\%) & $102(46.8)$ \\
\hline \multicolumn{2}{|l|}{ Race/ethnicity (\%) } \\
\hline Latinx & $178(81.7)$ \\
\hline African American & $17(7.8)$ \\
\hline Non-Hispanic white & $16(7.3)$ \\
\hline Other & $7(3.2)$ \\
\hline Annual household income $<\$ 15 \mathrm{~K}(\%)$ & $53(24.3)$ \\
\hline Owns home (\%) & $65(29.8)$ \\
\hline Lives with smoker (\%) & $42(19.3)$ \\
\hline \multicolumn{2}{|c|}{ Activity level compared to children their age (\%) } \\
\hline Less active & $20(9.2)$ \\
\hline About as active & $135(61.9)$ \\
\hline More active & $63(28.9)$ \\
\hline Overweight $^{a}$ & $42(19.3)$ \\
\hline Obese $^{a}$ & $64(29.4)$ \\
\hline \multicolumn{2}{|l|}{ Highest maternal education level (\%) } \\
\hline$<8$ th grade & $28(12.9)$ \\
\hline Some high school & $37(17.1)$ \\
\hline Completed high school or GED & $52(24.0)$ \\
\hline Some college & $54(24.9)$ \\
\hline Completed college & $35(16.1)$ \\
\hline Advanced degree & $11(5.1)$ \\
\hline
\end{tabular}

a Using age- and sex-specific percentiles of the 2000 CDC growth charts, obese was defined as $\mathrm{BMI} \geq 95$ th percentile and overweight was defined as BMI 85th to $<95$ th percentiles. assessing patterns in the pollutant-biomarker relationships rather than for individual pollutants presented.

For biomarkers of metabolic dysregulation, there was a consistent pattern of decreasing HDL with increasing pollutant exposure across multiple time frames (Table 2 and Fig. 1A). The largest decrease in HDL was seen in CO exposure averaged over the 3-month period $(-22.8 \mathrm{mg} / \mathrm{dL}$ per $0.5 \mathrm{ppm}$ increase in $\mathrm{CO} \mathrm{Cl}$ $=-44.1,-1.53)$ and $\mathrm{NO}_{2}$ exposure averaged over a 3-month period $\left(-15.4 \mathrm{mg} / \mathrm{dL}\right.$ per $9.3 \mathrm{ppb}$ increase in $\mathrm{NO}_{2}, 95 \% \mathrm{Cl}=-27.4$, -3.4). HDL consistently decreased in association with longer-term $\mathrm{NO}_{2}$ and $\mathrm{NO}_{x}$ exposure (3 months, 6 months, 1 year). Though some exposure windows did not reach statistical significance, there was also a consistent pattern of decreased HDL with increased longer-term exposure to $\mathrm{CO}, \mathrm{PAH} 456, \mathrm{EC}$, and $\mathrm{PM}_{2.5}$. Percent HbA1c showed a pattern of non-significant increases during 1-month exposure time frames for several pollutants (Table 3 and Fig. 1B): $\mathrm{NO}_{2}, \mathrm{PAH} 456, \mathrm{EC}, \mathrm{CO}$, and $\mathrm{PM}_{2.5}$.

Higher levels of 8-isoprostane were associated with short-term exposure to all measured traffic-related pollutants (Table 4 and Fig. 1C). The largest increase in 8-isoprostane was associated with 1-day lagged PAH456 exposure (1.5 times the 8-isoprostane level per $7.7 \mathrm{ng} / \mathrm{m}^{3}$ increase in $\left.\mathrm{PAH} 456,95 \% \mathrm{Cl}=1.1,2.1\right)$ and 1 -day lagged CO (1.3 times the 8-isoprostane level per $0.5 \mathrm{ppm}$ increase in $\mathrm{CO}, 95 \% \mathrm{Cl}=1.1,1.7)$. The 8 -isoprostane levels were primarily increased with short-term increases in pollutants; however, pollutant associations with 8-isoprostane dissipated at longer time frames ( 3 months to 1 year).

CC16 showed a consistent pattern of decreases associated with exposures to traffic-related pollutants, even when confidence intervals cross the null (Table 5 and Fig. 1D). Across all pollutants, the 3- to 6-month exposure time frames were associated with the largest decreases in CC16 level. The association with the largest magnitude was 6-month average EC exposure, a $0.2 \mu \mathrm{g} / \mathrm{m}^{3}$ increase in EC was associated with 0.5 times the CC16 level $(95 \% \mathrm{Cl}=0.3,0.8)$.

In sensitivity analyses, the pattern of findings was unchanged when CC16 was adjusted for creatinine. The pattern of findings was also robust to the choice of the smoothing function for seasonality.

\section{DISCUSSION}

In this well-characterized 9-year-old child cohort, we found a consistent pattern of decreased $\mathrm{HDL}$ cholesterol across all $\mathrm{NO}_{x}$ and $\mathrm{NO}_{2}$ exposure time frames and longer-term (1-, 3-month and 1-year) time frames for most pollutants, a pattern of elevated 8-isoprostane levels during short-term (1-day, 1-week) exposure periods, non-significant increases in percent $\mathrm{HbA} 1 \mathrm{c}$ during 1-month exposure time frames, and nonsignificant decreases in CC16 during 3-month exposure time frames. These results indicate a relationship between TRAP and markers of oxidative stress and metabolism in 9-year-old children, as previously found in this cohort at age 7, and possible associations with lung epithelial injury as well.

HDLs play a role in cardiovascular protective actions by eliminating excess cholesterol in arterial walls and providing anti-inflammatory properties [31]. Decreasing HDL cholesterol with increasing levels of air pollution in this study is consistent with previous adult epidemiologic studies demonstrating increased metabolic dysregulation associated with higher air pollutant exposure [32-34]. Other studies in pediatric populations have demonstrated associations between exposure to particulate matter, $\mathrm{NO}_{x}$ or combined pollutant indices with worsened biomarkers of metabolic dysregulation (plasma insulin, fasting glucose, oxidized low-density lipoprotein), and oxidative stress (malondialdehyde), as well as anthropometric measures (elevated BMI, systolic and diastolic blood pressure) $[19,35]$. However, the results in this study contrast those of a cross-sectional analysis conducted in an Italian birth cohort that found no association between TRAP and HDL cholesterol [36]. This may be attributable 


\begin{tabular}{|c|c|c|c|c|c|c|}
\hline Pollutant & 1-day average & 1-week average & 1-month average & 3-month average & 6-month average & 1-year average \\
\hline $\mathrm{NO}_{2}$ (ppb) IQRs & 9.4 & 10.1 & 9.7 & 9.3 & 6.0 & 2.2 \\
\hline Estimate & -5.10 & -4.60 & -0.10 & -15.40 & -7.90 & -3.10 \\
\hline $95 \% \mathrm{Cl}$ & $(-8.4,-1.8)$ & $(-8.7,-0.6)$ & $(-3.2,3)$ & $(-27.4,-3.4)$ & $(-15.4,-0.4)$ & $(-6.3,0.1)$ \\
\hline$P$ value & 0.003 & 0.026 & 0.95 & 0.013 & 0.041 & 0.057 \\
\hline $\mathrm{NO}_{x}(\mathrm{ppb}) \mathrm{IQRs}$ & 13.1 & 13.4 & 14.7 & 12.6 & 8.7 & 3.5 \\
\hline$P$ value & 0.404 & 0.027 & 0.06 & 0.042 & 0.022 & 0.018 \\
\hline PAH456 $\left(\mathrm{ng} / \mathrm{m}^{3}\right)$ IQRs & 7.7 & 7.9 & 8.4 & 7.9 & 5.2 & 0.8 \\
\hline Estimate & 0.20 & 0.10 & -0.40 & -4.90 & -2.70 & -1.40 \\
\hline $95 \% \mathrm{Cl}$ & $(-2.6,3.1)$ & $(-2.9,3.1)$ & $(-3.9,3)$ & $(-17.5,7.7)$ & $(-6.5,1.1)$ & $(-4.3,1.4)$ \\
\hline$P$ value & 0.869 & 0.957 & 0.81 & 0.448 & 0.163 & 0.327 \\
\hline $\mathrm{EC}\left(\mu \mathrm{g} / \mathrm{m}^{3}\right) \mathrm{IQRs}$ & 0.5 & 0.4 & 0.4 & 0.3 & 0.2 & 0.1 \\
\hline CO (ppm) IQRs & 0.5 & 0.6 & 0.6 & 0.5 & 0.3 & 0.1 \\
\hline Estimate & -2 & -2.6 & -0.4 & -22.8 & -5.4 & -2.2 \\
\hline $95 \% \mathrm{Cl}$ & $(-5.6,1.6)$ & $(-7.7,2.5)$ & $(-4,3.1)$ & $(-44.1,-1.5)$ & $(-14.9,4.2)$ & $(-5.2,0.7)$ \\
\hline$P$ value & 0.272 & 0.317 & 0.813 & 0.038 & 0.275 & 0.144 \\
\hline $\mathrm{PM}_{2.5}\left(\mu \mathrm{g} / \mathrm{m}^{3}\right)$ IQRs & 11.9 & 14.7 & 16.5 & 13.7 & 9.8 & 3.6 \\
\hline Estimate & 0 & 0.2 & 0.8 & -2.2 & -1.4 & -0.8 \\
\hline $95 \% \mathrm{Cl}$ & $(-0.9,0.9)$ & $(-1.1,1.5)$ & $(-1.3,2.9)$ & $(-7.5,3.1)$ & $(-3.5,0.8)$ & $(-3.3,1.6)$ \\
\hline$P$ value & 0.952 & 0.748 & 0.466 & 0.416 & 0.206 & 0.514 \\
\hline
\end{tabular}

All results are absolute changes in $\mathrm{HDL}(\mathrm{mg} / \mathrm{dL})$ per interquartile range (IQR) of the pollutant. These estimates come from a GAM model that adjusted for whether or not the child lives with a smoker, whether or not the child is Latinx, physical activity, household income, and a smoothed term for the day of study.

(A) Estimated change in $\mathrm{HDL}(\mathrm{mg} / \mathrm{dL})$
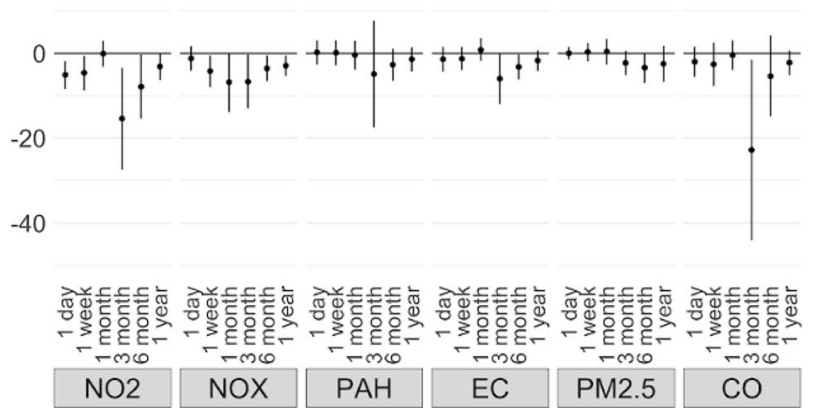

(C) Estimated change in creatinineadjusted 8-Isoprostane $(\mathrm{ng} / \mathrm{mg})$

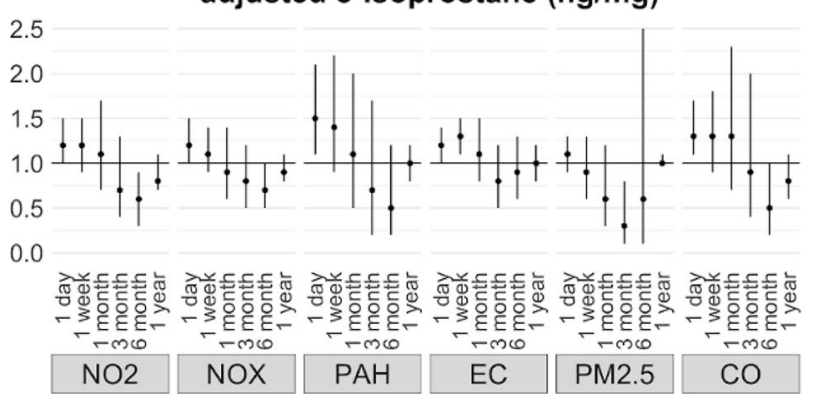

(B) Estimated change in HbA1c (\%)

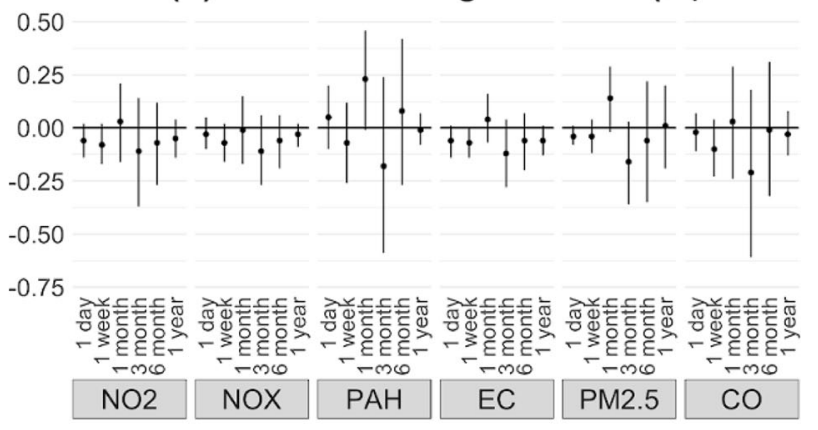

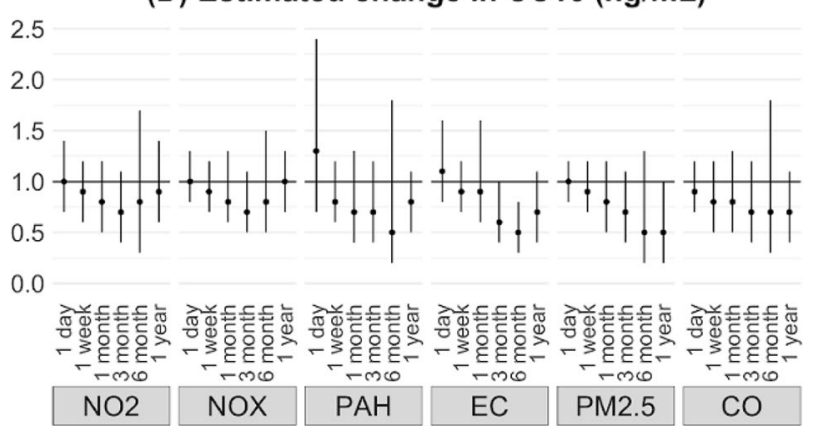

Fig. 1 Associations of 1-day, 1-week, 1-month, 3-month, 6-month, and 1-year averages of air pollutants with estimated. A Change in HDL $(\mathrm{mg} / \mathrm{dL})$, B change in HbA1c (\%), C multiplicative change in $\log _{\mathrm{e}}$ creatinine-adjusted 8-isoprostane (ng/mg), and D multiplicative change in $\log _{e}$ CC16 (ng/mL). 
Table 3. HbA1c generalized additive model results.

\begin{tabular}{|c|c|c|c|c|c|c|}
\hline Pollutant & 1-day average & 1-week average & 1-month average & 3-month average & 6-month average & 1-year average \\
\hline $\mathrm{NO}_{2}$ (ppb) IQRs & 9.4 & 10.1 & 9.7 & 9.3 & 6.0 & 2.2 \\
\hline Estimate & -0.06 & -0.08 & 0.03 & -0.11 & -0.07 & -0.05 \\
\hline $95 \% \mathrm{Cl}$ & $(-0.14,0.02)$ & $(-0.17,0.02)$ & $(-0.16,0.21)$ & $(-0.37,0.14)$ & $(-0.27,0.12)$ & $(-0.14,0.04)$ \\
\hline$P$ value & 0.12 & 0.12 & 0.78 & 0.39 & 0.46 & 0.31 \\
\hline $\mathrm{NO}_{x}(\mathrm{ppb})$ IQRs & 13.1 & 13.4 & 14.7 & 12.6 & 8.7 & 3.5 \\
\hline Estimate & -0.03 & -0.07 & -0.01 & -0.11 & -0.06 & -0.03 \\
\hline $95 \% \mathrm{Cl}$ & $(-0.1,0.05)$ & $(-0.16,0.02)$ & $(-0.17,0.15)$ & $(-0.27,0.06)$ & $(-0.19,0.06)$ & $(-0.09,0.02)$ \\
\hline$P$ value & 0.46 & 0.15 & 0.89 & 0.21 & 0.34 & 0.25 \\
\hline PAH456 $\left(\mathrm{ng} / \mathrm{m}^{3}\right)$ IQRs & 7.7 & 7.9 & 8.4 & 7.9 & 5.2 & 0.8 \\
\hline Estimate & 0.05 & -0.07 & 0.23 & -0.18 & 0.08 & -0.01 \\
\hline $95 \% \mathrm{Cl}$ & $(-0.1,0.2)$ & $(-0.26,0.12)$ & $(-0.01,0.46)$ & $(-0.59,0.24)$ & $(-0.27,0.42)$ & $(-0.08,0.07)$ \\
\hline$P$ value & 0.5 & 0.48 & 0.06 & 0.4 & 0.66 & 0.88 \\
\hline$E C\left(\mu \mathrm{g} / \mathrm{m}^{3}\right)$ IQRs & 0.5 & 0.4 & 0.4 & 0.3 & 0.2 & 0.1 \\
\hline Estimate & -0.06 & -0.07 & 0.04 & -0.12 & -0.06 & -0.06 \\
\hline $95 \% \mathrm{Cl}$ & $(-0.14,0.01)$ & $(-0.14,0)$ & $(-0.07,0.16)$ & $(-0.28,0.04)$ & $(-0.2,0.07)$ & $(-0.13,0.01)$ \\
\hline$P$ value & 0.1 & 0.04 & 0.47 & 0.13 & 0.37 & 0.1 \\
\hline $\mathrm{CO}(\mathrm{ppm}) \mathrm{IQRs}$ & 0.5 & 0.6 & 0.6 & 0.5 & 0.3 & 0.1 \\
\hline Estimate & -0.02 & -0.1 & 0.03 & -0.21 & -0.01 & -0.03 \\
\hline $95 \% \mathrm{Cl}$ & $(-0.11,0.07)$ & $(-0.23,0.04)$ & $(-0.24,0.29)$ & $(-0.61,0.18)$ & $(-0.32,0.31)$ & $(-0.13,0.08)$ \\
\hline$P$ value & 0.65 & 0.15 & 0.84 & 0.29 & 0.97 & 0.62 \\
\hline $\mathrm{PM}_{2.5}\left(\mu \mathrm{g} / \mathrm{m}^{3}\right) \mathrm{IQRs}$ & 11.9 & 14.7 & 16.5 & 13.7 & 9.8 & 3.6 \\
\hline Estimate & -0.04 & -0.04 & 0.14 & -0.16 & -0.06 & 0.01 \\
\hline $95 \% \mathrm{Cl}$ & $(-0.08,0.01)$ & $(-0.12,0.04)$ & $(-0.02,0.29)$ & $(-0.36,0.03)$ & $(-0.35,0.22)$ & $(-0.19,0.2)$ \\
\hline$P$ value & 0.1 & 0.32 & 0.09 & 0.09 & 0.67 & 0.93 \\
\hline
\end{tabular}

All results are absolute changes in \% hemoglobin A1c per interquartile range (IQR) of the pollutant. These estimates come from a GAM model that adjusted for whether or not the child lives with a smoker, whether or not the child is Latinx, physical activity, household income, and a smoothed term for day of study.

Table 4. 8-Isoprostane generalized additive model results.

\begin{tabular}{|c|c|c|c|c|c|c|}
\hline Pollutant & 1-day average & 1-week average & 1-month average & 3-month average & 6-month average & 1-year average \\
\hline $\mathrm{NO}_{2}$ (ppb) IQRs & 9.4 & 10.1 & 9.7 & 9.3 & 6.0 & 2.2 \\
\hline Estimate & 1.2 & 1.2 & 1.1 & 0.7 & 0.6 & 0.8 \\
\hline $95 \% \mathrm{Cl}$ & $(1,1.5)$ & $(0.9,1.5)$ & $(0.7,1.7)$ & $(0.4,1.3)$ & $(0.3,0.9)$ & $(0.7,1.1)$ \\
\hline$P$ value & 0.094 & 0.213 & 0.818 & 0.316 & 0.023 & 0.178 \\
\hline $\mathrm{NO}_{x}(\mathrm{ppb})$ IQRs & 13.1 & 13.4 & 14.7 & 12.6 & 8.7 & 3.5 \\
\hline Estimate & 1.2 & 1.1 & 0.9 & 0.8 & 0.7 & 0.9 \\
\hline $95 \% \mathrm{Cl}$ & $(1,1.5)$ & $(0.9,1.4)$ & $(0.6,1.4)$ & $(0.5,1.2)$ & $(0.5,1)$ & $(0.8,1.1)$ \\
\hline$P$ value & 0.021 & 0.246 & 0.752 & 0.234 & 0.048 & 0.236 \\
\hline PAH456 $\left(\mathrm{ng} / \mathrm{m}^{3}\right)$ IQRs & 7.7 & 7.9 & 8.4 & 7.9 & 5.2 & 0.8 \\
\hline Estimate & 1.5 & 1.4 & 1.1 & 0.7 & 0.5 & 1 \\
\hline $95 \% \mathrm{Cl}$ & $(1.1,2.1)$ & $(0.9,2.2)$ & $(0.5,2)$ & $(0.2,1.7)$ & $(0.2,1.2)$ & $(0.8,1.2)$ \\
\hline$P$ value & 0.019 & 0.089 & 0.87 & 0.4 & 0.136 & 0.832 \\
\hline EC $\left(\mu \mathrm{g} / \mathrm{m}^{3}\right) \mathrm{IQRs}$ & 0.5 & 0.4 & 0.4 & 0.3 & 0.2 & 0.1 \\
\hline Estimate & 1.2 & 1.3 & 1.1 & 0.8 & 0.9 & 1 \\
\hline $95 \% \mathrm{Cl}$ & $(1,1.4)$ & $(1.1,1.5)$ & $(0.8,1.5)$ & $(0.5,1.2)$ & $(0.6,1.3)$ & $(0.8,1.2)$ \\
\hline$P$ value & 0.03 & 0.013 & 0.548 & 0.338 & 0.447 & 0.734 \\
\hline $\mathrm{CO}(\mathrm{ppm}) \mathrm{IQRs}$ & 0.5 & 0.6 & 0.6 & 0.5 & 0.3 & 0.1 \\
\hline Estimate & 1.3 & 1.3 & 1.3 & 0.9 & 0.5 & 0.8 \\
\hline $95 \% \mathrm{Cl}$ & $(1.1,1.7)$ & $(0.9,1.8)$ & $(0.7,2.3)$ & $(0.4,2)$ & $(0.2,1)$ & $(0.6,1.1)$ \\
\hline$P$ value & 0.014 & 0.143 & 0.434 & 0.826 & 0.059 & 0.228 \\
\hline $\mathrm{PM}_{2.5}\left(\mu \mathrm{g} / \mathrm{m}^{3}\right)$ IQRs & 11.9 & 14.7 & 16.5 & 13.7 & 9.8 & 6.7 \\
\hline Estimate & 1.1 & 0.9 & 0.6 & 0.3 & 0.6 & 1 \\
\hline $95 \% \mathrm{Cl}$ & $(0.9,1.3)$ & $(0.6,1.3)$ & $(0.3,1.2)$ & $(0.1,0.8)$ & $(0.1,2.5)$ & $(1,1.1)$ \\
\hline$P$ value & 0.28 & 0.607 & 0.165 & 0.015 & 0.456 & 0.275 \\
\hline
\end{tabular}

All results are multiplicative changes in 8-isoprostane to creatinine ratio $(\mathrm{ng} / \mathrm{mg})$ per interquartile range (IQR) of the pollutant. These estimates come from a GAM model that adjusted for whether or not the child lives with a smoker, whether or not the child is Latinx, physical activity, household income, and a smoothed term for the day of study. 
Table 5. CC16 generalized additive model results.

\begin{tabular}{|c|c|c|c|c|c|c|}
\hline Pollutant & 1-day average & 1-week average & 1-month average & 3-month average & 6-month average & 1-year average \\
\hline $\mathrm{NO}_{2}$ (ppb) IQRs & 9.4 & 10.1 & 9.7 & 9.3 & 6.0 & 2.2 \\
\hline $95 \% \mathrm{Cl}$ & $(0.7,1.4)$ & $(0.6,1.2)$ & $(0.5,1.2)$ & $(0.4,1.1)$ & $(0.3,1.7)$ & $(0.6,1.4)$ \\
\hline $\mathrm{NO}_{x}(\mathrm{ppb})$ IQRs & 13.1 & 13.4 & 14.7 & 12.6 & 8.7 & 3.5 \\
\hline Estimate & 1.00 & 0.90 & 0.80 & 0.70 & 0.80 & 1.00 \\
\hline $95 \% \mathrm{Cl}$ & $(0.8,1.3)$ & $(0.7,1.2)$ & $(0.6,1.3)$ & $(0.5,1.1)$ & $(0.5,1.5)$ & $(0.7,1.3)$ \\
\hline Estimate & 1.30 & 0.80 & 0.70 & 0.70 & 0.50 & 0.80 \\
\hline $95 \% \mathrm{Cl}$ & $(0.7,2.4)$ & $(0.6,1.2)$ & $(0.4,1.3)$ & $(0.4,1.2)$ & $(0.2,1.8)$ & $(0.5,1.1)$ \\
\hline$P$ value & 0.47 & 0.36 & 0.27 & 0.19 & 0.33 & 0.17 \\
\hline$E C\left(\mu \mathrm{g} / \mathrm{m}^{3}\right)$ IQRs & 0.5 & 0.4 & 0.4 & 0.3 & 0.2 & 0.1 \\
\hline Estimate & 1.10 & 0.90 & 0.90 & 0.60 & 0.50 & 0.70 \\
\hline $95 \% \mathrm{Cl}$ & $(0.7,1.2)$ & $(0.5,1.2)$ & $(0.5,1.3)$ & $(0.4,1.2)$ & $(0.3,1.8)$ & $(0.4,1.1)$ \\
\hline$P$ value & 0.51 & 0.25 & 0.40 & 0.17 & 0.47 & 0.14 \\
\hline $\mathrm{PM}_{2.5}\left(\mu \mathrm{g} / \mathrm{m}^{3}\right) \mathrm{IQRs}$ & 11.9 & 14.7 & 16.5 & 13.7 & 9.8 & 3.6 \\
\hline Estimate & 1.00 & 0.90 & 0.80 & 0.70 & 0.50 & 0.50 \\
\hline $95 \% \mathrm{Cl}$ & $(0.8,1.2)$ & $(0.7,1.2)$ & $(0.5,1.2)$ & $(0.4,1.1)$ & $(0.2,1.3)$ & $(0.2,1)$ \\
\hline$P$ value & 0.84 & 0.44 & 0.30 & 0.11 & 0.18 & 0.05 \\
\hline
\end{tabular}

All results are multiplicative changes in $\mathrm{CC} 16(\mathrm{ng} / \mathrm{mL})$ per interquartile range (IQR) of the pollutant. These estimates come from a GAM model that adjusted for whether or not the child lives with a smoker, whether or not the child is Latinx, physical activity, household income, and a smoothed term for day of study.

to differences in study population characteristics, as in the Italian cohort, $9.29 \%$ were obese and overweight, while the CHAPS cohort has $48.7 \%$ obese and overweight children. It is possible that children who are overweight could be more sensitive to the effects of air pollution on HDL, as has previously been shown for air pollution effects on pediatric blood pressure [37]. The relationship between TRAP and HDL cholesterol in pediatric populations may be somewhat variable based on underlying population characteristics and is therefore worthy of further study.

TRAP exposure has been found in both experimental and epidemiologic studies to increase levels of reactive oxygen species that lead to higher levels of oxidative stress, resulting in degradation of important cellular molecules, such as lipids including HDL cholesterol $[8,33,38]$. For instance, an experimental study using cultured pulmonary alveolar macrophages exposed to PAHs indicated that these compounds were metabolized by cytochrome P450A1 into quinones contributing to the generation of reactive oxygen species, thereby increasing levels of oxidative stress [39]. This mechanism aligns with our study's results on urinary 8-isoprostane, a stable biomarker of lipid peroxidation, which was elevated in association with short-term exposure periods of most of the TRAP we studied, but the association dissipated for longer exposure averages. This is consistent with the known half-life of 8-isoprostane (roughly $16 \mathrm{~min}$ in serum, likely moderately longer in urine) [40]. Similarly, a large crosssectional study of 2035 adult participants in Framingham, MA, found that 3- to 7-day moving averages of black carbon (BC) and $\mathrm{NO}_{x}$ exposure were also shown to be associated with increased urinary 8-isoprostane [41]. Moreover, pediatric studies have also detected elevated concentrations of 8-isoprostane in exhaled breath condensates from children linked to BC exposure $[42,43]$. The prior CHAPS analyses looking at the cohort at age 7 found that short-term average TRAP exposure (1-day, 1-week, and 1month) was consistently and significantly associated with creatinine-adjusted urinary 8-isoprostane [23]. Of the four pollutants assessed in the prior analysis-EC, $\mathrm{NO}_{2}, \mathrm{PAH} 456$, and $\mathrm{PM}_{2.5}$-the findings for the first three were very similar to those of the current study approximately 2 years later, with more precision in the estimates in the larger cohort at age 7. Interestingly, there was not a clear association between $\mathrm{PM}_{2.5}$ exposure and increased 8-isoprostane in this analysis, whereas there had been at age 7 . These findings provide further evidence that air pollution can lead to oxidative stress in children as well as adults. Cytokine release from the inflammatory response to oxidative stress-induced lung injury can spill over into the circulatory system to cause systemic inflammation $[4,12]$ and increase risk for several chronic disorders, including metabolic syndrome, atherosclerotic cardiovascular disease, and type II diabetes [8].

$\mathrm{HbA1C}$ in this study showed a pattern of elevations associated with the 1-month moving average across several pollutants, most notably PAH456 and $\mathrm{PM}_{2.5}$, which can be attributed to circulating red blood cells having a life span of approximately 3-4 months [44]. Because red blood cells constantly turn over, the 1-month average will have a higher percentage of assayed cells that were present during that entire exposure duration, and this exposure window will represent most of the exposure window for half or more of the red cells present. The prior CHAPS paper analyzing the 7-year-old cohort found significant associations between 3- and 6-month TRAP exposure and increased percent changes of $\mathrm{HbA1c}$ [23]. In adults, air pollution exposure is thought to contribute to type II diabetes [1, 45, 46]. A recent birth cohort study found that prenatal exposure to $\mathrm{PM}_{2.5}$ was associated with increased $\mathrm{HbA} 1 \mathrm{c}$ levels in prepubertal children of ages 4-5 years, suggesting that this relationship could hold for recent exposure in older children as well [47]. Experimental animal studies observed exposure to particulate matter to be associated with changes in insulin sensitivity and amplified adipose inflammation in mouse models of diet-induced obesity [5], as well as induced in vivo expression of metabolic syndrome-related genes in mice, specifically genes related 
to inflammation, lipid and cholesterol metabolism, and atherosclerosis [48]. Based on this evidence from air pollution exposure in animal and epidemiology studies, insulin resistance, dyslipidemia, and central adiposity may be related to particulate matter exposure via inflammatory pathways. These findings contribute to the limited literature thus far assessing this pathway in children.

CC16, a biomarker of lung epithelial damage, is an antiinflammatory protein secreted from club cells in response to oxidative stress and inflammation [49]. We found a consistent trend of decreasing CC16 with longer exposure periods ( 3 and 6 months) but with several confidence intervals crossing the null. Studies have shown that chronic exposure to air pollution, and especially to tobacco smoke, is associated with lower levels of CC16 and increased risk of chronic obstructive pulmonary disease [50], while short-term exposure is associated with elevated levels of CC16 [51]. Because our outcomes were measured at one time point and associated with multiple pollutant exposure windows, it may be that effects in opposite directions obscure the short-term findings. In a longitudinal birth cohort study following participants from age 6-32, higher levels of early-life exposure to $\mathrm{NO}_{2}$ were associated with consistently lower levels of circulating $\mathrm{CC} 16$, indicating that increased $\mathrm{NO}_{2}$ exposure during childhood may impact critical windows of lung development [49]. Because prior studies suggest that CC16 may be associated with long-term exposure to air pollution and decreases in lung function, it is particularly important that this relationship continue to be explored.

This research study has several strengths. These include a comprehensive and high-quality set of exposure data (including novel pollutants such as ambient PAHs), as well as a careful assessment of biomarkers. This study also adds to the literature on health effects of pollution for children of color from low-income families.

Limitations include the cross-sectional analysis and relatively small sample size. Due to the large number of pollutants and exposure time frames, we mitigated the risk of type II errors from multiple comparisons by interpreting the results based on the general patterns of confidence intervals rather than looking at the significance level of each statistical test. A complete lipid panel for the study would have been preferable, but we tested only for HDL cholesterol instead since it does not require fasting prior to collection, creating less burden on participants.

Future avenues of research include running longitudinal analyses of the data from the CHAPS cohort at both ages 7 and 9. Longitudinal analyses were not practical for some of these outcomes as most of the cohort did not have HDL cholesterol and none had CC16 measurements at age 7. Longitudinal assessments of the biomarkers and anthropometric data available at both time points are forthcoming in a future analysis.

Overall, our results support the hypothesis that acute exposure to TRAP impacts metabolic function in children. Low-grade systemic inflammation is associated with metabolic syndrome in adults, and is an important factor in instigating premature atherosclerosis [52]. For this reason, it is crucial to consider whether early-life exposure to ambient air pollution could contribute to later-life cardiometabolic disease $[17,53]$. Evidence of linkage between TRAP exposure and the biomarkers measured in our study suggests that air pollution contributes to abnormal lipid and glucose metabolism in children, which may then lead to increased risk of metabolic syndrome in adulthood. This relationship between TRAP and metabolic function in children argues for public health actions that could further decrease exposures to air pollution during childhood.

\section{REFERENCES}

1. Bowe B, Xie Y, Li T, Yan Y, Xian H, Al-Aly Z. The 2016 global and national burden of diabetes mellitus attributable to PM2.5 air pollution. Lancet Planet Health. 2018;2:e301-12.
2. Rochlani Y, Pothineni NV, Kovelamudi S, Mehta JL. Metabolic syndrome: pathophysiology, management, and modulation by natural compounds. Ther Adv Cardiovasc Dis. 2017;11:215-25.

3. Park SK, Auchincloss AH, O'Neill MS, Prineas R, Correa JC, Keeler J, et al. Particulate air pollution, metabolic syndrome, and heart rate variability: the Multi-Ethnic Study of Atherosclerosis (MESA). Environ Health Perspect. 2010;118:1406-11.

4. Haberzettl $P, O$ 'Toole TE, Bhatnagar A, Conklin DJ. Exposure to fine particulate air pollution causes vascular insulin resistance by inducing pulmonary oxidative stress. Environ Health Perspect. 2016;124:1830-9.

5. Sun $Q$, Yue P, Deiuliis JA, Lumeng CN, Kampfrath T, Mikolaj MB, et al. Ambient air pollution exaggerates adipose inflammation and insulin resistance in a mouse model of diet-induced obesity. Circulation. 2009;119:538-46.

6. Alderete TL, Habre R, Toledo-Corral CM, Berhane K, Chen Z, Lurmann FW, et al. Longitudinal associations between ambient air pollution with insulin sensitivity, $\beta$-cell function, and adiposity in Los Angeles Latino Children. Diabetes. 2017;66:1789-96.

7. Mao S, Li S, Wang C, Liu Y, Li N, Liu F, et al. Is long-term PM1 exposure associated with blood lipids and dyslipidemias in a Chinese rural population? Environ Int. 2020;138:105637.

8. Hussain T, Tan B, Yin Y, Blachier F, Tossou MCB, Rahu N. Oxidative stress and inflammation: what polyphenols can do for us? Oxid Med Cell Longev. 2016;2016:7432797. https://www.hindawi.com/journals/omcl/2016/7432797/.

9. Chuang K-J, Chan C-C, Su T-C, Lee C-T, Tang C-S. The effect of urban air pollution on inflammation, oxidative stress, coagulation, and autonomic dysfunction in young adults. Am J Respir Crit Care Med. 2007;176:370-6.

10. Riggs DW, Zafar N, Krishnasamy S, Yeager R, Rai SN, Bhatnagar A, et al. Exposure to airborne fine particulate matter is associated with impaired endothelial function and biomarkers of oxidative stress and inflammation. Environ Res. 2020;180:108890.

11. Lao XQ, Guo C, Chang L-Y, Bo Y, Zhang Z, Chuang YC, et al. Long-term exposure to ambient fine particulate matter (PM2.5) and incident type 2 diabetes: a longitudinal cohort study. Diabetologia. 2019;62:759-69.

12. Miller MR, Shaw CA, Langrish JP. From particles to patients: oxidative stress and the cardiovascular effects of air pollution. Future Cardiol. 2012;8:577-602.

13. Kaufman JD, Spalt EW, Curl CL, Hajat A, Jones MR, Kim S-Y, et al. Advances in understanding air pollution and cardiovascular diseases: the Multi-Ethnic Study of Atherosclerosis and Air Pollution (MESA Air). Glob Heart. 2016;11:343-52.

14. Brook RD, Rajagopalan S, Pope CA, Brook JR, Bhatnagar A, Diez-Roux AV, et al. Particulate matter air pollution and cardiovascular disease. Circulation. 2010;121:2331-78.

15. Matz CJ, Egyed M, Hocking R, Seenundun S, Charman N, Edmonds N. Human health effects of traffic-related air pollution (TRAP): a scoping review protocol. Syst Rev. 2019;8:223.

16. Mao G, Nachman RM, Sun Q, Zhang X, Koehler K, Chen Z, et al. Individual and joint effects of early-life ambient PM2.5 exposure and maternal prepregnancy obesity on childhood overweight or obesity. Environ Health Perspect. 2017;125:067005.

17. Park SK. Ambient air pollution and type 2 diabetes: do the metabolic effects of air pollution start early in life? Diabetes. 2017;66:1755-7.

18. Toledo-Corral C, Alderete T, Habre R, Berhane K, Lurmann F, Weigensberg M, et al. Effects of air pollution exposure on glucose metabolism in Los Angeles minority children. Pediatr Obes. 2018;13:54-62.

19. Zhang J-S, Gui Z-H, Zou Z-Y, Yang B-Y, Ma J, Jing J, et al. Long-term exposure to ambient air pollution and metabolic syndrome in children and adolescents: a national cross-sectional study in China. Environ Int. 2021;148:106383.

20. Most polluted cities | State of the air. 2021. https://www.lung.org/research/sota/ city-rankings/most-polluted-cities. Accessed 6 Jul 2021.

21. U.S. Census Bureau QuickFacts: Fresno City, California. 2019. https://www.census. gov/quickfacts/fact/table/fresnocitycalifornia,fresnocountycalifornia/PST045219. Accessed 28 Mar 2021

22. Centers for Disease Control and Prevention. CDC health disparities and inequalities report-United States, 2013. MMWR Suppl. 2013;62:3-5.

23. Mann JK, Lutzker L, Holm SM, Margolis HG, Neophytou AM, Eisen EA, et al. Trafficrelated air pollution is associated with glucose dysregulation, blood pressure, and oxidative stress in children. Environ Res. 2021;195:110870.

24. SAS Program (ages 0 to $<20$ years) | Resources | Growth chart training | Nutrition | DNPAO | CDC. 2019. https://www.cdc.gov/nccdphp/dnpao/growthcharts/ resources/sas.htm. Accessed 20 Mar 2021

25. Martín-Granado A, Vázquez-Moncholí C, Luis-Yanes MI, López-Méndez M, GarcíaNieto V. Determination of Clara cell protein urinary elimination as a marker of tubular dysfunction. Pediatr Nephrol. 2009;24:747-52.

26. Tran V, Tindula G, Huen K, Bradman A, Harley K, Kogut K, et al. Prenatal phthalate exposure and 8-isoprostane among Mexican-American children with high prevalence of obesity. J Dev Orig Health Dis. 2017;8:196-205. 
27. FirstCarbon Solutions. Section 5.3. City of Fresno general plan and development code update air quality master environmental impact report. 2014. https://www. fresno.gov/darm/wp-content/uploads/sites/10/2016/11/Sec-05-03-Air-QualityMEIR.pdf. Accessed 29 Mar 2021.

28. Noth EM, Hammond SK, Biging GS, Tager IB. A spatial-temporal regression model to predict daily outdoor residential PAH concentrations in an epidemiologic study in Fresno, CA. Atmos Environ. 2011;45:2394-403.

29. Noth EM, Lurmann F, Perrino C, Vaughn D, Minor HA, Hammond SK. Decrease in ambient polycyclic aromatic hydrocarbon concentrations in California's San Joaquin Valley 2000-2019. Atmos Environ. 2020;242:117818.

30. San Joaquin Valley APCD Home Page. 2012. https://www.valleyair.org/Home.htm. Accessed 28 Mar 2021.

31. Rosenson RS, Brewer HB, Ansell BJ, Barter P, Chapman MJ, Heinecke JW, et al Dysfunctional HDL and atherosclerotic cardiovascular disease. Nat Rev Cardiol. 2016;13:48-60.

32. Li J, Zhou C, Xu H, Brook RD, Liu S, Yi T, et al. Ambient air pollution is associated with HDL (high-density lipoprotein) dysfunction in healthy adults. Arterioscler Thromb Vasc Biol. 2019;39:513-22.

33. Araujo JA, Barajas B, Kleinman M, Wang X, Bennett BJ, Gong KW, et al. Ambient particulate pollutants in the ultrafine range promote early atherosclerosis and systemic oxidative stress. Circ Res. 2008;102:589-96.

34. Li W, Dorans KS, Wilker EH, Rice MB, Kloog I, Schwartz JD, et al. Ambient air pollution, adipokines, and glucose homeostasis: the Framingham Heart Study. Environ Int. 2018;111:14-22.

35. Kelishadi R, Mirghaffari N, Poursafa P, Gidding SS. Lifestyle and environmental factors associated with inflammation, oxidative stress and insulin resistance in children. Atherosclerosis. 2009;203:311-9.

36. Fioravanti S, Cesaroni G, Badaloni C, Michelozzi P, Forastiere F, Porta D. Trafficrelated air pollution and childhood obesity in an Italian birth cohort. Environ Res. 2018;160:479-86.

37. Dong G-H, Wang J, Zeng X-W, Chen L, Qin X-D, Zhou Y, et al. Interactions between air pollution and obesity on blood pressure and hypertension in Chinese children. Epidemiol Camb Mass. 2015;26:740-7.

38. Bell G, Mora S, Greenland P, Tsai M, Gill E, Kaufman JD. Association of air pollution exposures with high density lipoprotein cholesterol and particle number: the MultiEthnic Study of Atherosclerosis. Arterioscler Thromb Vasc Biol. 2017;37:976-82.

39. Aust AE, Falahee KJ, Maher VM, McCormick JJ. Human cell-mediated benzo(a) pyrene cytotoxicity and mutagenicity in human diploid fibroblasts. Cancer Res. 1980;40:4070-5.

40. Basu S. The enigma of in vivo oxidative stress assessment: isoprostanes as an emerging target. Scand J Food Nutr. 2007;51:48-61.

41. Li W, Wilker EH, Dorans KS, Rice MB, Schwartz J, Coull BA. et al. Short-term exposure to air pollution and biomarkers of oxidative stress: the Framingham Heart Study. J Am Heart Assoc. 2016:5:e002742.

42. De Prins S, Dons E, Van Poppel M, Int Panis L, Van de Mieroop E, Nelen V, et al. Airway oxidative stress and inflammation markers in exhaled breath from children are linked with exposure to black carbon. Environ Int. 2014;73:440-6.

43. Rosa MJ, Yan B, Chillrud SN, Acosta LM, Divjan A, Jacobson JS, et al. Domestic airborne black carbon levels and 8-isoprostane in exhaled breath condensate among children in New York City. Environ Res. 2014;135:105-10.

44. Sherwani SI, Khan HA, Ekhzaimy A, Masood A, Sakharkar MK. Significance of $\mathrm{HbA1C}$ test in diagnosis and prognosis of diabetic patients. Biomark Insights. 2016;11:95-104.

45. Eze IC, Schaffner E, Foraster M, Imboden M, von Eckardstein A, Gerbase MW, et al Long-term exposure to ambient air pollution and metabolic syndrome in adults. PloS One. 2015;10:e0130337.

46. Pearson JF, Bachireddy C, Shyamprasad S, Goldfine AB, Brownstein JS. Association between fine particulate matter and diabetes prevalence in the U.S. Diabetes Care. 2010;33:2196-201.

47. Moody EC, Cantoral A, Tamayo-Ortiz M, Pizano-Zárate ML, Schnaas L, Kloog I, et al. Association of prenatal and perinatal exposures to particulate matter with changes in hemoglobin A1c levels in children aged 4 to 6 years. JAMA Netw Open. 2019;2:e1917643.

48. Brocato J, Sun H, Shamy M, Kluz T, Alghamdi MA, Khoder Ml, et al. Particulate matter from Saudi Arabia induces genes involved in inflammation, metabolic syndrome and atherosclerosis. J Toxicol Environ Health A. 2014;77:751-66.

49. Broeckaert F, Bernard A. Clara cell secretory protein (CC16): characteristics and perspectives as lung peripheral biomarker. Clin Exp Allergy. 2000;30:469-75.

50. Lam DC-L, Kwok H-H, Yu W-C, Ko FW-S, Tam C-Y, Lau AC-W, et al. CC16 levels correlate with cigarette smoke exposure in bronchial epithelial cells and with lung function decline in smokers. BMC Pulm Med. 2018;18:47.

51. Madsen C, Durand KL, Nafstad P, Schwarze PE, Rønningen KS, Håheim LL. Associations between environmental exposures and serum concentrations of Clara cell protein among elderly men in Oslo, Norway. Environ Res. 2008;108:354-60.
52. Marsland AL, McCaffery JM, Muldoon MF, Manuck SB. Systemic inflammation and the metabolic syndrome among middle-aged community volunteers. Metabolism. 2010;59:1801-8.

53. Fleisch AF, Luttmann-Gibson H, Perng W, Rifas-Shiman SL, Coull BA, Kloog I, et al. Prenatal and early life exposure to traffic pollution and cardiometabolic health in childhood. Pediatr Obes. 2017;12:48-57.

\section{ACKNOWLEDGEMENTS}

The authors would like to thank the members of the Balmes research group (Raj Fadadu, Shreya Thatai, Graham Flitz, Ruwan Thilakaratne, and Alexandra Tien-Smith) for their advice and comments; the UCSF-Fresno research team (Griselda Aguilar, Christian Bonilla, Karina Corona, Cynthia Cortez, Alexa Lopez, Carolina Orozco, and Janna Blaauw) for their hard work in conducting the clinical visits; Barune Thapa, Hazel Lam, and Ana Diaz for their assistance with data entry; long-time collaborators Kari Nadeau and Mary Prunicki for their handling of laboratory samples; Cindy Tran Arthur Pavlovsky, and Olivia Yale for their assistance with blood and urine analyses in the Nina Holland laboratory; Charles Perrino and Patton Nguyen for the PAH analyses and media preparation in the Hammond laboratory; and all of the participating children and families for their patience and dedication to the study.

\section{AUTHOR CONTRIBUTIONS}

ALZ wrote the initial draft of the manuscript; ALZ and SMH performed data analysis and data interpretation together; LL, JKM, and TT led data collection; LL and JKM performed data management; $\mathrm{HGM}$ and $\mathrm{NH}$ performed the biomarker assays; $\mathrm{EMN}, \mathrm{FL}$, and $\mathrm{SKH}$ conducted the air pollution exposure assessment; JRB conceived the study, supervised the overall conduct of the study, and supervised the writing of the manuscript. All authors reviewed drafts and contributed to the writing of the manuscript.

\section{FUNDING INFORMATION}

This research was supported by the Children's Health and Air Pollution Study (CHAPS), an NIH/EPA-funded Children's Environmental Health Research Center (EPA: RD83543501, NIH: ES022849) and two additional grants (NIH: R24 ES030888 and NIH: R33 ES024719). The content is solely the responsibility of the authors and does not necessarily represent the official views of the National Institutes of Health.

\section{COMPETING INTERESTS}

The authors declare no competing interests.

\section{ADDITIONAL INFORMATION}

Supplementary information The online version contains supplementary material available at https://doi.org/10.1038/s41370-021-00378-6.

Correspondence and requests for materials should be addressed to S.M.H.

Reprints and permission information is available at http://www.nature.com/ reprints

Publisher's note Springer Nature remains neutral with regard to jurisdictional claims in published maps and institutional affiliations.

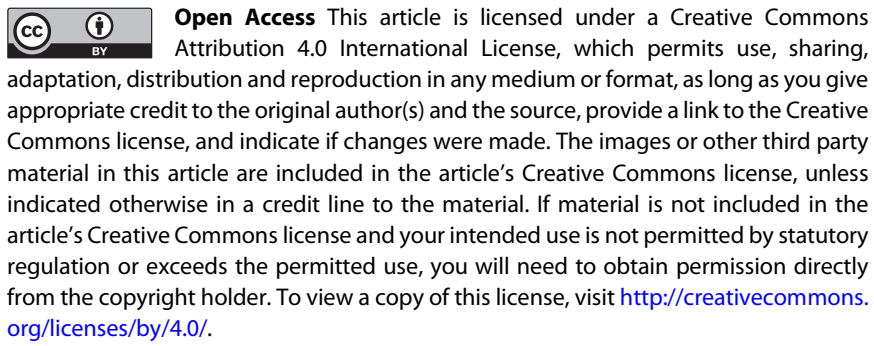

(c) The Author(s) 2021 